\title{
A especificação do desempenho e vida útil dos sistemas de pintura externa de acordo com a norma brasileira de desempenho - NBR 15575
}

\author{
Specification of the performance and service life of \\ external painting systems according to the Brazilian \\ performance standard - NBR 15575
}

\section{Mateus Flores Bordin \\ Elvira Maria Vieira Lantelme Marcelo Fabiano Costella}

\section{Resumo}

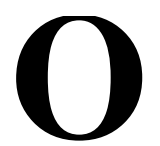

objetivo do artigo é identificar e expor as barreiras e dificuldades na determinação e especificação do desempenho e vida útil dos sistemas de pintura externa de acordo com as exigências da NBR 15575. O método de pesquisa consistiu na verificação dos catálogos digitais e fichas técnicas disponibilizados pelos fabricantes das tintas, entrevistados projetistas responsáveis pela especificação dos documentos técnicos de edificação, averiguados os manuais de uso, operação e manutenção dos incorporadores. Após, elaborou-se um artefato denominado de mapa mental para ser utilizado pelos fornecedores, projetistas, construtores e usuários. Dentre os resultados, os fabricantes não especificaram a vida útil de seus produtos e os projetistas especificaram de forma prescritiva, relacionando tal prática à falta de informações de desempenho dos produtos. Os prazos estipulados pelos construtores nos manuais para execução da repintura das superfícies estão em desacordo com a vida útil mínima exigida pela norma de desempenho. O mapa mental representou a interligação entre os intervenientes do sistema de pintura externa, evidenciando os processos que não atendem às normas e que contribuem para que as tarefas subsequentes da cadeia executiva não atendam aos requisitos de desempenho.

Palavras-chave: Sistemas de pintura. Especificação. Desempenho. Vida útil. Manutenção.

\begin{abstract}
The aim of this article is to identify and present the barriers and difficulties in determining and specifying the performance and service life of external painting systems according to the requirements of NBR 15575. The research method included an analysis of the digital catalogues and technical files made available by paint manufacturers, interviews with the designers responsible for the specifications of the technical building documents, as well as an analysis of the use, operation and maintenance manuals created by the developers. After, a device called Mind Map was created for use by suppliers, designers, builders, and users. The results showed that the manufacturers failed to specify the products' service life and the designers specified it in a prescriptive way, relating this practice to lack of information on the performance of the products. The builders' deadlines stipulated in the manuals for repainting buildings' surfaces are at odds with the minimum service life required by the performance standard. The Mind Map developed represented the interconnection between the actors of the external painting system, showing which processes that do not meet the normative requirements and contribute to the failure of the subsequent tasks of the executive chain in meeting the requirements of the performance standard.
\end{abstract}

Recebido em 15/05/20 Aceito em 01/04/21 Porto Alegre, v. 21, n. 4, p. 125-142, out./dez. 2021. 


\section{Introdução}

Desde a edição da norma de desempenho (NBR 15575) em 2008, com o efetivo vigor a partir de 2013, a construção civil brasileira vem passando por uma série de mudanças, desde a segregação de responsabilidades entre os intervenientes até práticas de especificação de projeto e prazos mínimos de desempenho e vida útil exigidos pela norma. Apesar de apresentar várias vantagens para o setor, essas mudanças necessitam de um ambiente técnico mais refinado e envolvem mudanças desde o processo de projeto e produção, na fiscalização e na forma de especificação dos fornecedores (KERN; SILVA; KAZMIERCZAK, 2014).

Apesar da norma de desempenho ter o objetivo de impulsionar ganho de qualidade e padrão às edificações habitacionais brasileiras, os projetistas e incorporadores/construtoras têm relatado dificuldades em atendê-la, em relação ao processo de projeto e à implantação pelas construtoras e incorporadoras (BELÉM; STARLING; ANDERY, 2018; PAGLIARI et al., 2019). Outro ponto com dificuldades de entendimento é a vida útil de projeto, que contém o conceito de durabilidade da edificação, a qual é influenciada por diversos fatores, entre eles condições climáticas, qualidade da construção, correta utilização dos materiais, adequada especificação técnica, bem como a constante manutenção preventiva/corretiva (LEWRY; CREWDSON, 1994; SHERWIN, 2000; OLIVEIRA PRIMO, 2008; ABNT, 2012).

O sistema de vedação vertical externa deve ter uma vida útil de projeto (VUP) de, no mínimo, 40 anos (ABNT, 2013a), que inclui a vedação externa, as esquadrias, o revestimento argamassado e a camada de acabamento. O emprego da pintura como sistema de acabamento em edificações habitacionais é uma das soluções mais comumente aplicadas devido às características estéticas e às funções de proteção e salubridade das edificações (ALMEIDA, 2012). Para o sistema de pinturas externas, a VUP mínima exigida pela NBR 15575-1 (ABNT, 2013a) é de 8 anos.

Dentre as dificuldades para implantação da norma de desempenho nesse sistema, a fase executiva possui inadequado detalhamento de projeto e planejamento para execução dos sistemas de pintura, o que reflete em incertezas nas tomadas de decisões no canteiro de obras, contribuindo para improvisos e decisões impróprias ou negligentes no canteiro de obra, o que pode resultar em uma série de manifestações patológicas precoces nos sistemas de pintura (POLITO, 2006). Os fabricantes de tintas expõem dificuldade na determinação da vida útil por conta das incertezas contidas na fase executiva e imperfeições do substrato, conforme relato do setor técnico da Associação Brasileira dos Fabricantes de Tintas (Abrafati). Além disso, existem incertezas no processo de manutenção do sistema, o qual, além de proporcionar o prolongamento na vida útil, requer o planejamento, a gestão, a organização e o controle dos recursos utilizados (OLIVEIRA, 2016).

De acordo com estudo de Marques de Jesus (2008), os gastos com manutenção predial no Brasil estão entre $1 \%$ a $2 \%$ do custo total das edificações, sendo que as despesas com reabilitação dos sistemas de vedação vertical podem representar uma faixa de $14 \%$ a $35 \%$ dos gastos com manutenção. Esses dados reforçam o volume dos investimentos dentro do setor de manutenção da construção e apontam para a necessidade de aumento da durabilidade dos sistemas que compõem as edificações (FRANGOPOL, 2011), assim como preconiza a norma de desempenho.

Dada a importância do desempenho dos sistemas de pintura em edifícios habitacionais, a presente pesquisa insere-se em um projeto de investigação de critérios de especificação dos intervenientes da construção: projetistas, construtores/incorporadores e fornecedores de material. A proposição é de que, caso seja assegurada a durabilidade das tintas, aliada à prática de especificação de projeto (levando em conta o desempenho) e de um plano de manutenção apropriado, a vida útil do sistema tende a ser prolongada, reduzindo o surgimento de manifestações patológicas e, como consequência, o consumo de recursos financeiros e naturais em intervenções corretivas.

Assim, o objetivo é identificar e expor as barreiras e dificuldades na determinação e especificação do desempenho e vida útil dos sistemas de pintura externa de acordo com as exigências feitas pela norma NBR 15575-1 (ABNT, 2013a). Este estudo fez uma análise de dados técnicos dos produtos, práticas de especificação de projeto e planos de manutenção, contribuindo para o desenvolvimento e a identificação dos pontos falhos no processo de especificação por desempenho, orientando possíveis avanços necessários na cadeia interveniente para que os sistemas de pintura atendam ao desempenho mínimo exigido pela norma. 


\section{Fundamentação teórica}

\section{Durabilidade e vida útil}

A especificação de vida útil prevista em projeto para sistemas e elementos construtivos deve ser compatível com a durabilidade dos materiais empregados, sendo necessário o conhecimento aprofundado a respeito do comportamento dos sistemas por parte dos projetistas (SHERWIN, 2000; MAYER; BOURKE, 2005; BORGES, 2008). Além da durabilidade dos materiais, a vida útil dos sistemas é dependente de diversos fatores como projeto adequado, qualidade na execução, agentes ambientais, uso adequado e planos de manutenção preventiva (OLIVEIRA PRIMO, 2008; TAVARES, 2009; OLIVEIRA; FONTENELLE; MITIDIERI FILHO, 2014).

A norma de desempenho (ABNT, 2013a) aponta que a vida útil de protejo (VUP) é determinada pelo período que o sistema é projetado para atendimento dos critérios exigidos pela normatização. Ao final, a vida útil do sistema é uma composição da vida útil teórica de projeto alterada positivamente ou negativamente pelos aspectos variáveis da ação do usuário, intempéries e planos de manutenção (CORDOVIL, 2013). A norma parametriza a VUP a partir de três fatores: o efeito causado pela falha do sistema/elemento, a facilidade de manutenção e o custo para intervenção corretiva, levando em conta a possibilidade de a falha prejudicar outros sistemas. Dessa forma, a norma classifica a VUP para as partes da edificação, conforme apresentado no Quadro 1. A VUP também pode ser considerada uma matéria de caráter econômico na construção civil, possibilitando aos usuários a opção por soluções de melhor custobenefício ao longo da utilização dos edifícios (BRASIL; SALGADO, 2012). Além disso, a durabilidade deve ser compatível com a VUP do sistema, sendo que compete ao projetista especificar em projeto ou memorial descritivo o valor teórico de VUP, condições de uso e exposição do edifício, possibilitando uma análise da VUP e da durabilidade dos sistemas que compõem a edificação (COSTELLA, 2018).

Para que a vida útil de projeto mínima estabelecida na NBR 15575-1 (ABNT, 2013a) possa ser atendida, é necessário cumprir cinco aspectos básicos: emprego de componentes e materiais de qualidade compatível com a VUP, execução com técnicas e métodos que possibilitem a obtenção da VUP, cumprimento em sua totalidade dos programas de manutenção corretiva e preventiva, atendimento aos cuidados preestabelecidos para se fazer um uso correto do edifício e utilização do edifício em concordância ao que foi previsto em projeto (CÂMARA..., 2013).

As características de desempenho das edificações deverão ser mantidas a partir de um programa de manutenção adequado (YIU, 2008). O programa de manutenção deve especificar o tipo de manutenção, os materiais que necessitam de manutenção especial e um programa periódico de inspeção deverão ser anexados ao manual do usuário ou livro da edificação (RESENDE; BARROS; MEDEIROS, 2001; ABNT, 2012). Esse programa deve estar contido no manual de uso, operação e manutenção de acordo com os preceitos da NBR 14037 (ABNT, 2014).

\section{Sistemas de pintura externa}

A NBR 13245 (ABNT, 2011) oferece orientações para a execução de pinturas em edificações não industriais, além de recomendar o sistema de pintura apropriado para diferentes substratos/superfícies. O sistema pintura exerce grande influência no desenho do espaço construído. Além de sua principal função de proteção das paredes das edificações, também expressa características de apelo estético (POLITO, 2006).

Quadro 1 - Prazos de VUP

\begin{tabular}{|c|c|c|c|c|}
\hline \multirow{2}{*}{ Parte da edificação } & \multirow{2}{*}{ Exemplos } & \multicolumn{3}{|c|}{ VUP (anos) } \\
\hline & & Mínimo & Intermed. & Superior \\
\hline \multirow[b]{2}{*}{ Pintura } & Pinturas internas e papel de parede & $\geq 3$ & $\geq 4$ & $\geq 5$ \\
\hline & $\begin{array}{l}\text { Pinturas de fachada, pinturas e } \\
\text { revestimentos sintéticos texturizados }\end{array}$ & $\geq 8$ & $\geq 10$ & $\geq 12$ \\
\hline $\begin{array}{l}\text { Revestimento de fachada } \\
\text { aderido e não aderido }\end{array}$ & $\begin{array}{l}\text { Revestimentos, molduras, componentes } \\
\text { decorativos e cobre-muros }\end{array}$ & $\geq 20$ & $\geq 25$ & $\geq 30$ \\
\hline Vedação externa & $\begin{array}{l}\text { Paredes de vedação externas, painéis de } \\
\text { fachada, fachadas-cortina }\end{array}$ & $\geq 40$ & $\geq 50$ & $\geq 60$ \\
\hline
\end{tabular}

Fonte: adaptado de NBR 15575-1 (ABNT, 2013a, p. 55). 
Os sistemas de pintura são tipicamente constituídos pelo substrato, fundos, líquidos preparadores de paredes, massas e, por fim, a tinta/textura de acabamento. Cada um desses elementos possui função definida e são responsáveis pelo desempenho final do sistema (BRITEZ, 2007; GIUDICE; PEREYRA, 2015).

Para especificar adequadamente os sistemas de pintura, é necessário definir o tipo de substrato e o ambiente no qual será realizada a pintura - meio interno ou externo, clima seco ou úmido, ambiente agressivo ou não agressivo (CUNHA, 2011) - em conjunto com as orientações referentes às classificações e aos requisitos conforme a NBR 11702 (ABNT, 2019a).

Além dessas considerações, deve-se observar o comportamento das cores. As cores mais vivas (orgânicas), especialmente verde e azul, podem desbotar após pouco tempo de aplicação, pois são mais vulneráveis à radiação solar, favorecendo no realce das imperfeições do substrato. Em contrapartida, as cores pastéis (inorgânicas) possuem maior durabilidade de cor (POLITO, 2006).

Segundo Almeida (2012), para um bom desempenho em sistemas de pintura, relacionam-se quatro fatores básicos que são influenciados segundo as condições do projeto, clima, substrato, tinta e mão de obra: resistência à ação da água, resistência aos agentes agressivos, elasticidade e compatibilidade mecânica e química do substrato.

\section{Manifestações patológicas em sistemas de pintura externa}

A maioria das anomalias construtivas costuma se manifestar nos elementos de contato com o ambiente externo, por exemplo, fachadas (LUND; LAMEGO, 2008). Das manifestações patológicas encontradas nos elementos de fachada, as fissuras apareceram com maior índice de frequência (cerca de 40\%), seguido pelo descolamento dos revestimentos (20\%) e irregularidades no acabamento (20\%) (CARRARO; DIAS, 2014; WALDHELM, 2014). Os sistemas de pintura aparecem caracterizados como material de acabamento, $(20 \%$ das manifestações patológicas) que tem como principais sintomas a perda de cor, o descascamento e o surgimento de bolhas (WALDHELM, 2014).

Conforme apurado por Segat (2005), nas paredes da fachada que recebem manutenção de pintura ocorre uma redução de, aproximadamente, $63 \%$ nas manifestações patológicas com relação às paredes sem manutenção, justificando a importância e a necessidade de desempenho adequado e planos de manutenção dos sistemas de pintura. Entretanto, Almeida (2012) destaca que a utilização da repintura de superfícies como procedimento de manutenção deve ser evitada, pois torna a película da tinta muito espessa e, consequentemente, mais quebradiça.

Lund e Lamego (2008) rastrearam a origem das manifestações patológicas encontradas nas edificações, reconhecendo que $52 \%$ são originárias de falhas na execução, $31 \%$ nas especificações de projeto e $17 \%$ materiais inadequados e ambientes agressivos. Carraro e Dias (2014) apontam que as manifestações patológicas se originam de $40 \%$ dos trabalhos de execução, 30\% por falhas na especificação de projetos, $20 \%$ uso e operação e $10 \%$ materiais inadequados.

Com relação ao uso e à operação, Waldhelm (2014) expõe que 51\% das anomalias encontradas nas edificações habitacionais podem ser remetidas à ausência de planos de manutenção adequados. Grandiski (2004) relata que $40 \%$ das manifestações patológicas corriqueiras podem ser evitadas ainda em fase de projeto, evidenciando a importância da especificação de projeto adequada dos sistemas de pintura.

\section{Método de pesquisa}

A estratégia de pesquisa utilizada foi uma pesquisa qualitativa, de natureza descritiva, que gerou como resultado o mapa mental. O delineamento da pesquisa (Figura 1) consistiu na coleta de dados em catálogos digitais e fichas técnicas disponibilizados pelos fabricantes de tintas, a investigação de como os projetistas especificam a durabilidade e a manutenção dos sistemas de pintura e as especificações contidas no manual de uso, operação e manutenção das edificações no âmbito das incorporadoras. Os resultados foram compilados em um mapa mental, sendo este avaliado em um workshop para aprimoramento de sua estrutura, organização e interligação dos resultados. Por fim, foram definidas as contribuições práticas e teóricas do estudo. Cada etapa da pesquisa encontra-se detalhada ao longo deste capítulo.

128 Bordin, M. F.; Lantelme, E. M. V.; Costella, M. F. 
Figura 1 - Delineamento da pesquisa

COLETA DE DADOS:
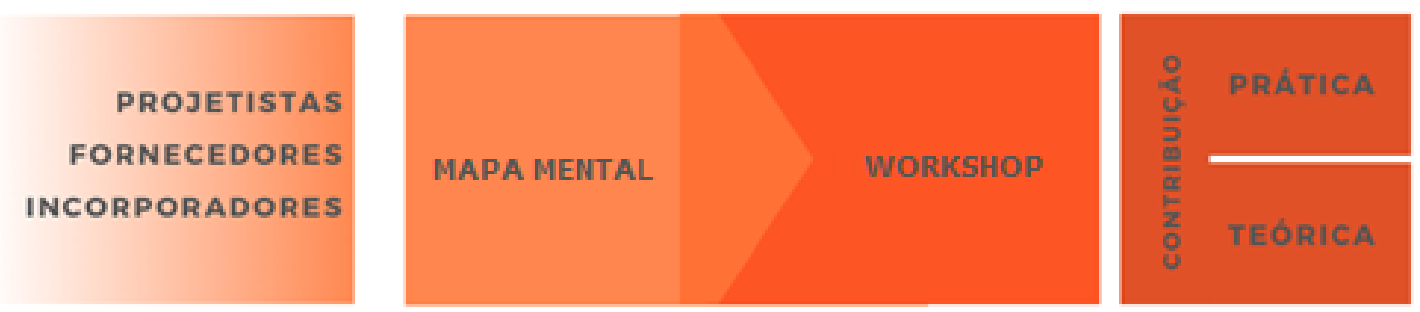

REVISÃo DE LITERATURA INICIAL COMPLEMENTAR

\section{Coleta de dados}

\section{Atendimento à NBR 15575 por parte dos fabricantes de tinta}

Para a escolha dos fornecedores investigados, extraiu-se uma lista de todos os fabricantes de tintas (principal componente dos sistemas de pintura) cadastrados na Associação Brasileira dos Fabricantes de Tintas (Abrafati). A Abrafati possui uma carteira composta por 33 fabricantes de tintas. Como a pesquisa visou os fornecedores de tinta para substratos argamassados em edifícios habitacionais, foram eliminados da lista os fornecedores de tintas para componentes metálicos, madeiras, telhas e pisos, restando 25 fabricantes.

Os fornecedores foram avaliados, primeiramente, a partir de uma análise dos dados dispostos ao público pelos fornecedores, tanto na embalagem dos produtos, como catálogos técnicos e diretórios eletrônicos. Além dos aspectos de manutenibilidade e durabilidade das tintas, foram analisados também os boletins técnicos dos produtos, com relação aos cuidados e procedimentos de aplicação dos produtos. Os boletins técnicos foram categorizados em três classificações quanto à especificidade das informações, sendo:

(a) muito breve, quando expostos apenas dados e taxas a respeito da diluição do produto;

(b) breve, para informações de diluição, espessura das camadas, número ideal de demãos e rendimento do produto; e

(c) detalhado, nas ocasiões em que, além de todas as informações já mencionadas, apresentou os critérios e cuidados durante a aplicação do produto, ferramentas necessárias, aspectos do substrato e condições climáticas.

A segunda fase foi instituída via e-mail por meio de questões referentes ao cumprimento das exigências impostas pela NBR 15575-1 (ABNT, 2013a) para o aspecto de durabilidade dos materiais no que diz respeito à caracterização do desempenho de seus produtos. Por fim, realizou-se o contato telefônico com esses fornecedores buscando consolidar as respostas obtidas e entender quais as dificuldades e os desafios na adaptação do mercado pós-norma. Assim, os dados foram coletados separadamente para cada fornecedor, registrando cada participante com a denominação "Fabricante" seguido de um número sequencial de registro $(1,2$, etc.).

\section{Avaliação de manuais de uso, operação e manutenção (incorporadores/ construtores)}

A análise do manual de uso, operação e manutenção de edificações habitacionais objetivou avaliar as especificações e manutenções propostas pelos incorporadores, responsáveis por tal documento. Para isso, a primeira etapa consistiu em definir a amostra de maneira não probabilística por conveniência, direcionando a coleta dos manuais às incorporadoras que executam obras residenciais associadas ao Sindicato da Indústria da Construção Civil (Sinduscon) das cidades de Passo Fundo (RS) e Chapecó (SC). Como resultado foram identificadas 49 incorporadoras, sendo 31 (trinta e um) em Passo Fundo e 18 (dezoito) na cidade de Chapecó. Tais cidades foram escolhidas por serem as regiões de atuação profissional dos pesquisadores. 
A segunda etapa consistiu em realizar o contato via e-mail com as 49 incorporadoras, solicitando a disponibilização de um manual de uso, operação e manutenção de edificações que tiveram o protocolo de projeto construtivo registrado após a vigência da norma de desempenho (julho de 2013). Em resposta, 19 (dezenove) disponibilizaram seus manuais, sendo 10 (dez) de Passo Fundo e 9 (nove) de Chapecó.

Por fim, a terceira etapa foi composta pela elaboração de critérios para avaliação dos manuais, a partir de uma lista de verificação dos aspectos especificados nas normas vigentes para os requisitos mínimos de durabilidade, planos manutenção e prazos de garantia dos sistemas de pintura, os quais foram baseados na pesquisa desenvolvida por Pallaoro et al. (2018) e adaptados exclusivamente para o sistema de pinturas. Assim sendo, os critérios para avaliação dos manuais de uso, operação e manutenção foram: existe um programa de manutenção para o sistema de pintura com prazos e procedimentos a serem executados? $\mathrm{O}$ manual contempla o contato e as informações do fabricante da tinta já aplicada? Existem orientações de como se avaliar a necessidade de manutenção corretiva dos sistemas de pintura? Os prazos de garantia estão de acordo com a NBR 15575-1 (ABNT, 2013a)? As ações e condições que resultam na perda de garantia estão expostas e atendem à norma NBR 14037 (ABNT, 2014)? Com relação ao aspecto de manutenibilidade, o manual prevê pontos para acesso ou ancoragem de equipamentos para instalação e execução dos serviços? Com isso, os resultados foram categorizados em três classes:

(a) confere $(\mathrm{C})$;

(b) não confere (NC); e

(c) confere parcialmente $(\mathrm{CP})$.

\section{Entrevistas com projetistas}

As entrevistas presenciais com projetistas foram focadas nos responsáveis pelas especificações da vida útil de projeto e respectivas manutenções necessárias. A primeira etapa consistiu em definir a amostra de maneira não probabilística por conveniência, de modo que foram agendadas entrevistas com 13 projetistas, sendo 5 de Chapecó (SC) e 8 da cidade de Passo Fundo (RS). Dos profissionais abordados, 10 possuíam formação em Arquitetura e Urbanismo e 3 em Engenharia Civil. Além disso, 5 atestaram experiência profissional de pelo menos 4 anos, e 8 profissionais com mais de 8 anos de experiência em especificação de projeto. O principal critério desta etapa foi com relação à seleção dos participantes, na qual se buscou que os entrevistados fossem de fato os responsáveis efetivos por executarem as tarefas de especificações técnicas no memorial descritivo, memória de cálculo ou manual de uso, operação e manutenção.

As respostas foram gravadas pelo entrevistador e, a partir da transcrição das respostas, realizou-se a técnica de pesquisa denominada análise de conteúdo para extração das informações. A entrevista foi conduzida com base no roteiro elaborado por Pagliari, Costella e Pilz (2018), apresentado no Quadro 2, de maneira semiestruturada com abordagem indireta, na qual o respondente conhece parcialmente os objetivos do projeto, seguindo um roteiro de questões abertas de caráter qualitativo, tendo como principais características: a variabilidade de respostas e a flexibilidade e a interação entre os envolvidos, o que faz com que a capacidade de interpretação do entrevistador seja um dos aspectos mais relevantes nesse método. Além de perguntas pontuais a respeito do sistema de pintura, os projetistas responderam discursivamente a respeito dos aspectos de mercado pós-implementação da norma, apresentaram sugestões para ensaios e procedimentos complementares à norma, para facilitar a avaliação de desempenho. Por fim, discutiram-se quais os aspectos necessários para que os sistemas de pintura passem a ser especificados por desempenho.

\section{Mapa mental}

Para a compilação das informações obtidas nesse estudo, nos estágios anteriores da pesquisa, elaborou-se um mapa mental, de modo a relacionar os aspectos influentes no processo de composição de um sistema de pintura e apresentar e destacar fatores que contribuem ou não para atendimento às exigências normativas. $\mathrm{O}$ mapa mental foi elaborado com o auxílio do software XMind (versão 8), caracterizando hierarquicamente todos os aspectos por texto, cores e formas das informações obtidas ao longo de todo o estudo. 


\section{Quadro 2 - Roteiro para entrevista com os projetistas}

\begin{tabular}{|c|c|}
\hline 1 & $\begin{array}{l}\text { Memorial de cálculo - Memorial descritivo - Manual de uso, operação e manutenção. Quais } \\
\text { desses memoriais técnicos você é responsável pela especificação? }\end{array}$ \\
\hline 2 & $\begin{array}{l}\text { A vida útil de projeto (VUP) é uma estimativa do período do tempo de vida útil em que o } \\
\text { projetista é responsável pelas decisões com maiores repercussões ao longo do ciclo de vida da } \\
\text { edificação. Na elaboração dos seus projetos, está realizando especificações considerando a vida } \\
\text { útil de projeto dos sistemas de pintura? (Sim/Não/Em alguns) }\end{array}$ \\
\hline 3 & $\begin{array}{l}\text { A Norma de Desempenho (NBR 15575-1) estabelece os valores de vida útil de projeto mínima, } \\
\text { intermediária e superior dos sistemas de pintura. O que você está fazendo ou faria de diferente } \\
\text { para atender aos prazos de vida útil de projeto estabelecidos na Norma? Quais as dificuldades? } \\
\text { (Discursiva) }\end{array}$ \\
\hline 4 & $\begin{array}{l}\text { Dada a importância e influência das atividades de manutenção no prolongamento da vida útil } \\
\text { dos materiais, a Norma de Desempenho apresenta três tipos distintos de manutenção: de rotina, } \\
\text { corretiva e preventiva. A manutenção de rotina envolve a realização de manutenções periódicas } \\
\text { da edificação pelo usuário, através de um manual de uso, operação e manutenção da edificação } \\
\text { com informações do fornecedor e do construtor. A manutenção preventiva é de responsabilidade } \\
\text { do projetista e está relacionada com as manutenções dos sistemas da edificação, como, por } \\
\text { exemplo, a definição do tempo de repintura da fachada e se haverá ou não uma lavagem da } \\
\text { fachada para conservar as propriedades do sistema. Como você especifica e com que critérios } \\
\text { define os planos de manutenção do sistema de pintura? (Discursiva) }\end{array}$ \\
\hline 5 & $\begin{array}{l}\text { É função do projetista estabelecer quais materiais/produtos atendem ao desempenho mínimo da } \\
\text { edificação. Como você especifica os materiais e produtos que compõem o sistema de pintura? } \\
\text { (Discursiva) }\end{array}$ \\
\hline 6 & $\begin{array}{l}\text { A norma de Desempenho ressalta que é de responsabilidade do fornecedor do sistema } \\
\text { caracterizar o seu desempenho e, consequentemente, dos materiais empregados. Você tem a } \\
\text { prática de consultar com o fabricante a vida útil dos materiais especificados nos seus projetos? } \\
\text { Se sim, para quais materiais encontrou a especificação? (Discursiva) }\end{array}$ \\
\hline 7 & $\begin{array}{l}\text { Com relação à especificação por desempenho e desenvolvimento de novas soluções, você já } \\
\text { desenvolveu/submeteu algum material a ensaios laborais para obtenção de propriedades não } \\
\text { especificadas pelo fabricante? Descreva. (Discursiva). }\end{array}$ \\
\hline 8 & $\begin{array}{l}\text { Você sugere algum ensaio ou procedimento para que as informações técnicas e comportamentais } \\
\text { dos materiais componentes do sistema de pintura sejam compreendidas e classificadas quanto a } \\
\text { durabilidade e vida útil? (Discursiva) }\end{array}$ \\
\hline 9 & $\begin{array}{l}\text { Na sua opinião, quais passos precisam ser dados para que os sistemas de pintura passem a ser } \\
\text { especificados por desempenho atendendo à vida útil mínima exigida pela NBR } 15575-1 \text { ? }\end{array}$ \\
\hline
\end{tabular}

Fonte: adaptado de Pagliari, Costella e Pilz (2018).

Dentre as versões que foram propostas, desde o início ficou definido que seria focada nas relações entre os fornecedores, projetistas, construtores/incorporadores e usuários, os quais foram dispostos nessa ordem de modo retangular em sentido horário. As informações de responsabilidade de cada interveniente foram classificadas em grupos, sendo três para os fabricantes (boletim técnico, NBR 15575 e Abrafati), duas para projetistas (memorial descritivo e projeto executivo) e construtor/incorporador (execução e manual de uso, operação e manutenção) e uma para os usuários (manutenções). Essas informações foram classificadas em um sistema de cores, sendo que a cor vermelha identifica os aspectos que não atendem às exigências normativas e às necessidades da cadeia produtiva; na cor amarela os aspectos que parcialmente satisfazem as mesmas condições; na cor verde os aspectos que foram considerados satisfatórios. A mesma classificação de cores foi utilizada para as flechas que indicam o fluxo das informações, ou seja, se elas estão sendo atendidas (verde), parcialmente atendidas (amarela) ou não atendidas (vermelha).

Assim, o mapa mental identificou as relações entre os principais dados levantados na pesquisa, assim como a interdependência entre eles e como isso afeta os demais aspectos subsequentes da cadeia de tarefas.

\section{Workshop}

Como forma de avaliar e melhorar a estrutura do artefato para apresentação dos dados coletados nas etapas anteriores, foi realizado um workshop de 4 horas composto por 24 participantes, sendo um especialista em implementação da NBR 15575-1 (ABNT, 2013a) em construtoras, um engenheiro projetista responsável por 
especificar o memorial descritivo de edificações habitacionais, um construtor encarregado de elaborar o manual de uso, operação e manutenção de edificações (com mais de 10 anos de experiência no mercado), os autores da pesquisa e alunos do Mestrado em Engenharia Civil da IMED (campus Passo Fundo). A condução do workshop teve como objetivo a discussão da estrutura do artefato e interligação dos aspectos primários e fatores secundários e terciários que influenciam o desempenho do sistema de pintura externa em substratos argamassados, a partir do ponto de vista dos quatro intervenientes apontados pela norma de desempenho: fornecedores, projetistas, construtores/incorporadores e usuários. Por fim, após o workshop foi definida a versão final do mapa mental de modo a representar a complexidade entre os aspectos técnicos e a cadeia de intervenientes.

\section{Contribuição teórica e prática}

Ao final, como forma de reflexão do estudo, foram compiladas as contribuições teóricas e práticas do estudo, que serão apresentadas nas considerações finais.

\section{Apresentação dos resultados}

\section{Atendimento à NBR 15575 por parte dos fabricantes de tinta}

Em análise aos documentos dispostos pelos 25 fornecedores de tinta selecionados, apenas um (1) deles apresentou prazos de durabilidade do material em aplicação, 12 declararam não possuir dados de durabilidade, vida útil e sequer validade dos seus produtos, 9 fabricantes expuseram que possuem um prazo de durabilidade estimado de seus produtos, porém sem ensaios ou documentos de comprovação, enquanto um (1) dos fornecedores exibiu apenas documentação relacionada à validade dos produtos ainda na embalagem. Por fim, um (1) fabricante de tinta comprovou com documentação técnica o prazo de durabilidade do produto, o qual atendia adequadamente ao período mínimo exigido pela norma.

Com relação aos planos de manutenção, nenhum dos entrevistados concordou com a existência de um prazo padrão, mas consentiram que cada ambiente e cada situação em particular deveriam possuir um plano preventivo. Contudo, um (1) dos fornecedores expôs a documentação referente a dados de durabilidade dos produtos, satisfazendo as condições normativas. Porém, quando questionado a respeito dos ensaios, procedimentos e técnicas para determinar a durabilidade das tintas, o fornecedor preferiu omitir informações por questões comerciais, mas ressalta que todas as orientações dispostas nos boletins técnicos dos produtos devem ser cumpridas para que o prazo de durabilidade seja atingido em sua totalidade. Por fim, a Tabela 1 apresenta resumidamente todas as informações coletadas com relação às abordagens realizadas com os fabricantes de tintas.

Tabela 1 - Prazos de VUP e manutenção obtidos dos fabricantes de tinta

\begin{tabular}{c|l|l|c}
\hline \multirow{2}{*}{ Fabricante } & \multicolumn{1}{|c|}{ Meio de obtenção do dado } & \multicolumn{2}{c}{ Pintura Externa } \\
\cline { 3 - 4 } & & \multicolumn{1}{c}{ VUP } & Manutenção \\
\hline 22 & Base digital e contato telefônico & 10 anos & 1 ano \\
\hline 8 & E-mail & 8 anos & 3 anos \\
\hline 11 & Contato telefônico & 8 anos & 3 anos \\
\hline 14 & Contato telefônico & 6 anos & 3 anos \\
\hline 2 & E-mail & 2 a 5 anos & - \\
\hline 21 & Base digital e contato telefônico & 3 anos & - \\
\hline 18 & Contato telefônico & 3 anos & - \\
\hline 19 & E-mail & 3 anos & - \\
\hline 5 & Contato telefônico & 2 anos & 2 anos \\
\hline 3 & Contato telefônico & 2 anos & - \\
\hline 10 & E-mail & 2 anos & - \\
\hline 23 & Contato telefônico & 2 anos & - \\
\hline 20 & Base digital & - & 1 ano \\
\hline $1,4,6,7,9,12,13$, & Base digital, e-mail e contato & - & - \\
$15,16,17,24,25$ & telefônico & - & \\
\hline
\end{tabular}

132 Bordin, M. F.; Lantelme, E. M. V.; Costella, M. F. 
Já para a análise do detalhamento dos procedimentos executivos contidos no boletim técnico dos produtos, classificou-se como $28 \%$ muito breve, $32 \%$ breve e $40 \%$ detalhado. Assim, quase metade dos fornecedores apresentaram as informações de diluição, espessura das camadas, número ideal de demãos, rendimento do produto, os critérios e cuidados durante a aplicação do produto, ferramentas necessárias, aspectos do substrato e condições climáticas.

\section{Avaliação de manuais de uso, operação e manutenção (incorporadores/ construtores)}

Dos 19 manuais de uso, operação e manutenção analisados, $21 \%$ foram classificados como não conformes, principalmente por não apresentarem procedimentos para execução de manutenções do sistema de pintura, croquis ou desenhos esquemáticos que representam posições ou locais de instalações e equipamentos e por não exporem de forma clara a necessidade/obrigatoriedade do usuário ou o responsável pela gestão do edifício em registrar ou documentar todas as intervenções, seja de manutenção ou reparo realizados dentro da edificação. Já os demais manuais (79\%) foram classificados como conformes parcialmente devido à explanação superficial das informações de manutenção, tornando-se inaplicáveis por usuários sem a especialidade técnica; não apresentaram também um quadro ou uma listagem indicativa com os incumbentes pelo desempenho ao longo da vida útil dos sistemas. Já para o aspecto de manutenibilidade, apenas $11 \%$ dos manuais previam pontos para acesso ou ancoragem de equipamentos para instalação ou execução dos serviços.

Apesar de 84\% dos manuais analisados apresentarem um plano de manutenção, as informações e orientações com relação aos sistemas de pintura eram superficiais. Constatou-se que nenhum manual foi compatível com a VUP mínima exigida pela NBR 15575-1 (ABNT, 2013a) para os sistemas de pintura. Em análise ao Quadro 1 (prazos de VUP), o sistema de pintura interna deve possuir uma VUP mínima de pelo menos 3 anos, e para pinturas externas o prazo é de 8 anos. Dos manuais analisados, 63\% expuseram como procedimento de manutenção a repintura de toda a superfície externa no período de 2 anos. Já outros 32\% dos manuais solicitaram repintura das superfícies internas a cada 6 meses e para as superfícies em contato com ambiente externo a cada um (1) ano. Por fim, 5\% dos manuais não especificaram áreas internas ou externas, requisitando repintura a cada 2 anos de todas as superfícies pintadas.

A delegação de tarefas e seus respectivos responsáveis foi um aspecto falho na maioria dos manuais, pois apenas $11 \%$ dos manuais expuseram de maneira clara o responsável por executar e inspecionar os serviços de manutenção, o que tende a dificultar a gestão, uma vez que não existe um responsável declarado. Já para as informações do sistema utilizado e contato dos fabricantes, todos os manuais atenderam ao critério, pois todas as construtoras informaram o fabricante e o respectivo contato, facilitando a comunicação no processo de gestão do plano de manutenção.

\section{Entrevistas com projetistas}

A partir das entrevistas, foi possível identificar que dos 13 entrevistados, 4 eram responsáveis por especificar a memória de cálculo, memorial descritivo e manual de uso, operação e manutenção das edificações, 6 apenas memorial descritivo e 3 apenas manual de uso, operação e manutenção. Foi possível observar que, mesmo nas construtoras no qual os profissionais são responsáveis por elaborar os três documentos técnicos das edificações, o manual de uso, operação e manutenção raramente é elaborado pelo mesmo profissional que elabora os demais memoriais.

Dos entrevistados, 9 atestaram positivamente o emprego da VUP, 2 entrevistados apontaram a utilização da VUP apenas em situações pontuais e específicas nas quais o projeto exige a determinação da vida útil mínima por conta da utilização e fator de segurança pré-determinados e 2 entrevistados alegaram que não especificam a VUP por entenderem que essa responsabilidade seja da fase executiva.

Durante a entrevista, alguns projetistas apontaram que as especificações de manutenção são definidas pelas práticas da construtora, em concordância aos prazos de validade estipulados pelos fabricantes dos produtos utilizados. Para os sistemas de pintura, os entrevistados destacaram que é de costume transcrever as especificações dispostas pelos fabricantes (quando os dados estiverem disponíveis). Na totalidade, os entrevistados apontam como as únicas ações para manutenção dos sistemas de pintura a lavagem com água (preventiva) ou a repintura da superfície (corretiva). 


\section{Mapa mental}

No intuito de compilar, relacionar e apresentar as informações, a Figura 2 apresenta o mapa mental com a rastreabilidade de todos os dados obtidos durante o estudo. Como característica básica, é possível observar que toda informação que chega na forma inadequada, parcial ou satisfatória se mantém com as mesmas características no processo de saída, ou seja, o processo tende a ser dependente das características do processo anterior. No mapa mental podem-se observar os aspectos que estão ligados pelas setas indicativas do sentido da informação no fluxo, como, por exemplo: o aspecto "informações de embalagem", sob responsabilidade do fabricante, influencia diretamente no aspecto "controle de qualidade", que está sob responsabilidade do construtor no canteiro de obras.

Em uma análise global, identifica-se uma tendência no fluxo das informações que inicia com os fabricantes que desenvolvem subsídios influentes nas tarefas praticadas pelos projetistas e construtores. Já os projetistas desempenham funções com impactos nos construtores e usuários. Por fim, os construtores têm ligação direta frente às suas ações e práticas com os usuários.

\section{Discussão dos resultados}

Devido à quantidade de processos identificados que envolvem o sistema de pintura, para melhor entendimento, a discussão será apresentada separadamente para os aspectos não atendidos, representados na cor vermelha, para os aspectos parcialmente suficientes, na cor amarela, e para os fatores considerados atendidos, na cor verde, sendo representados nas Figuras 3, 4 e 5, respectivamente.

Figura 2 - Mapa mental com as informações obtidas no estudo e com a interligação entre os aspectos técnicos

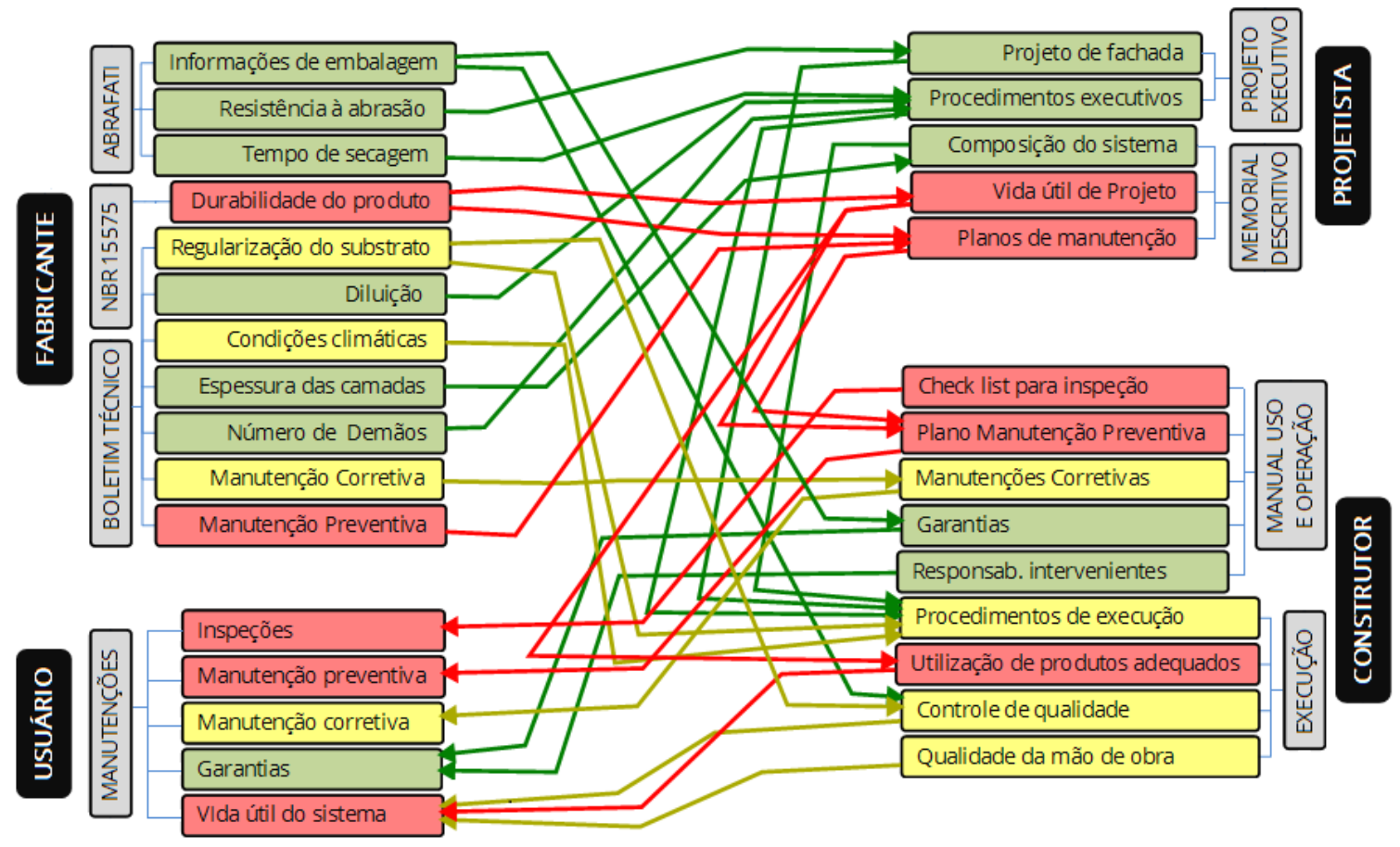

Aspectos atendidos com relação ao processo de pintura e normas ABNT
Aspectos parcialmente atendidos com relação ao processo de pintura e normas ABNT
Aspectos em descordo com relação ao processo de pintura e normas ABNT 
Figura 3 - Aspectos em desacordo com as necessidades normativas e de processo

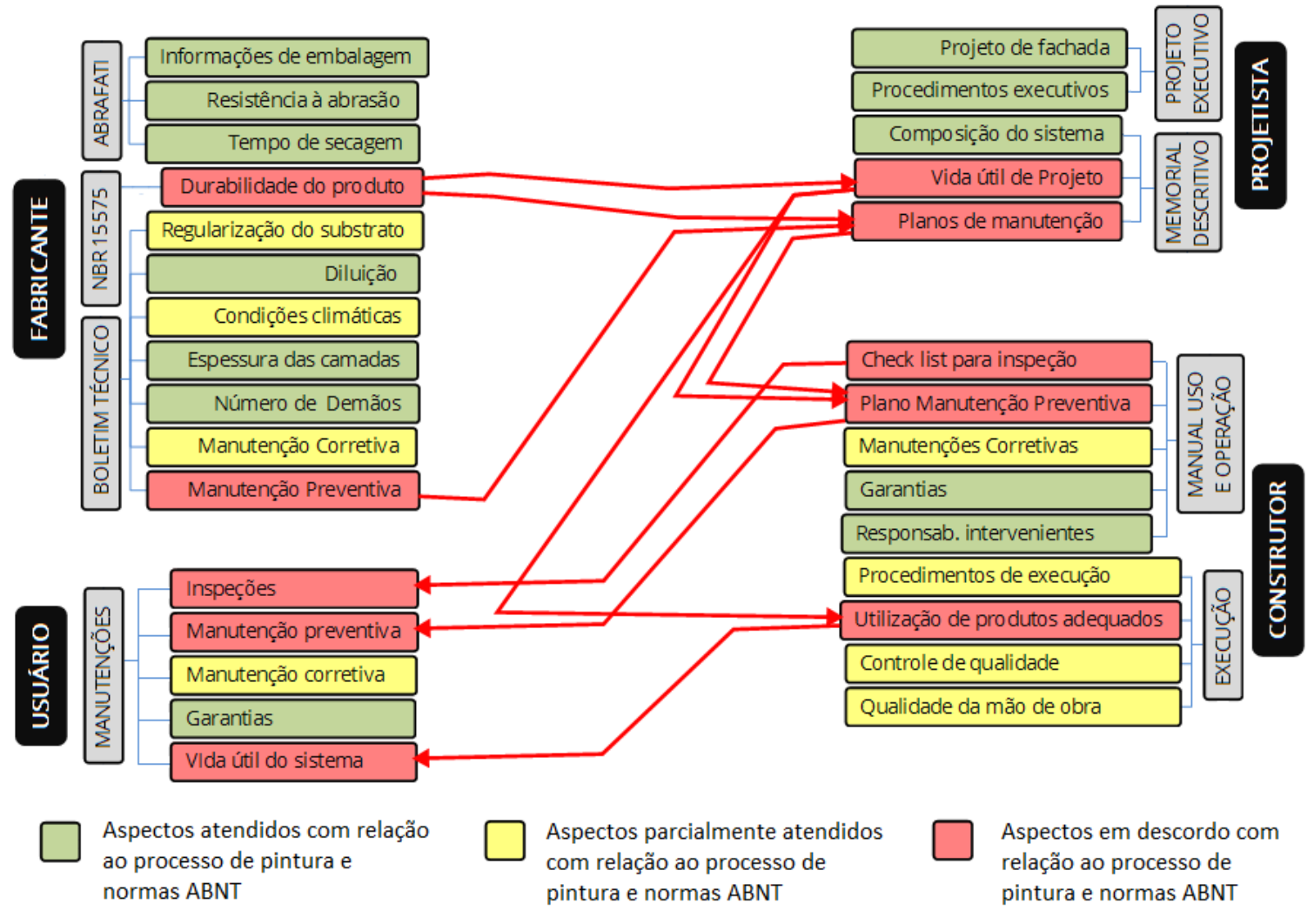

Figura 4 - Aspectos parcialmente atendidos com relação às necessidades normativas e de processo

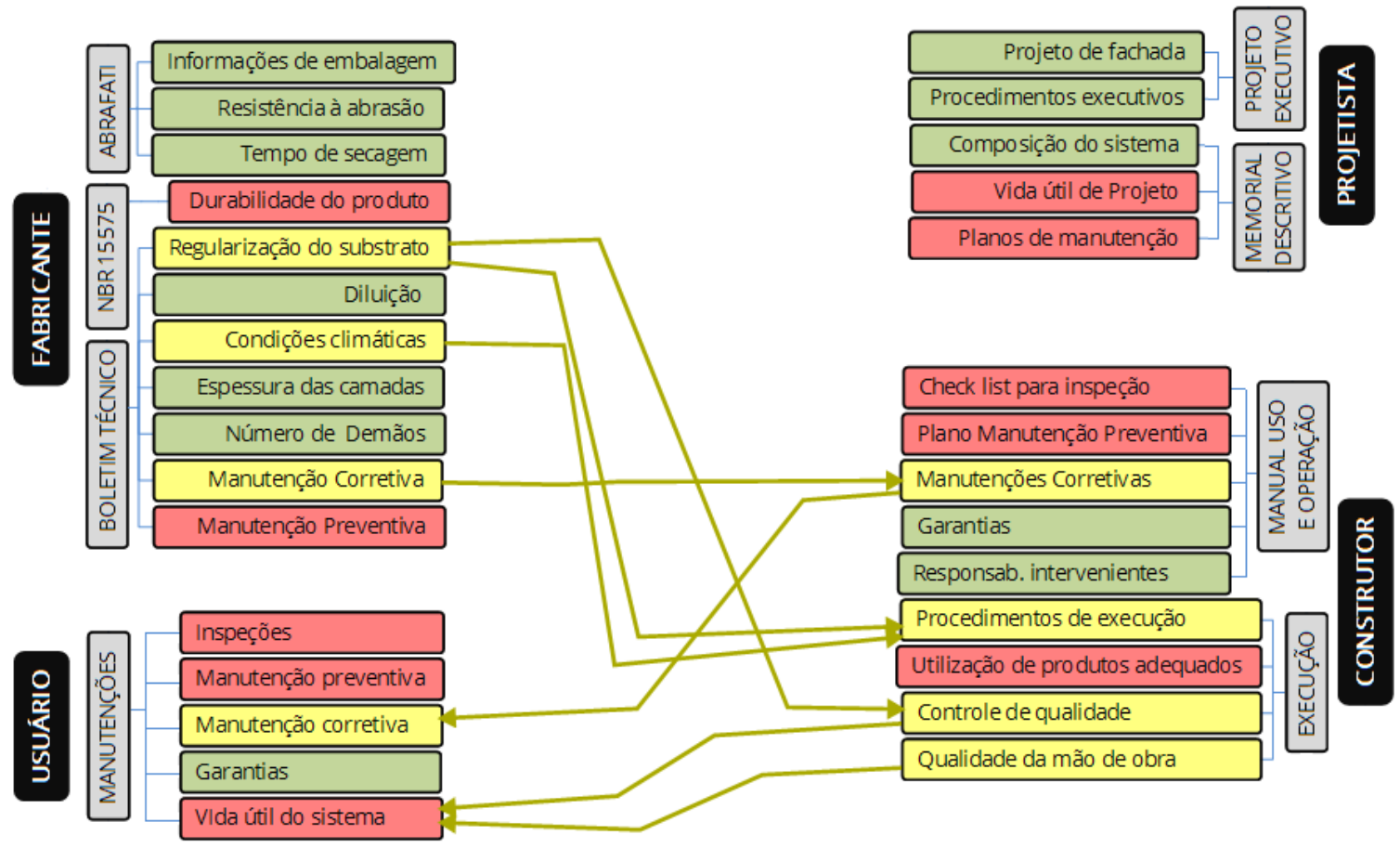

Aspectos atendidos com relação ao processo de pintura e normas ABNT
Aspectos parcialmente atendidos com relação ao processo de pintura e normas ABNT
Aspectos em descordo com relação ao processo de pintura e normas ABNT 
Figura 5 - Aspectos atendidos com relação às necessidades normativas e de processo

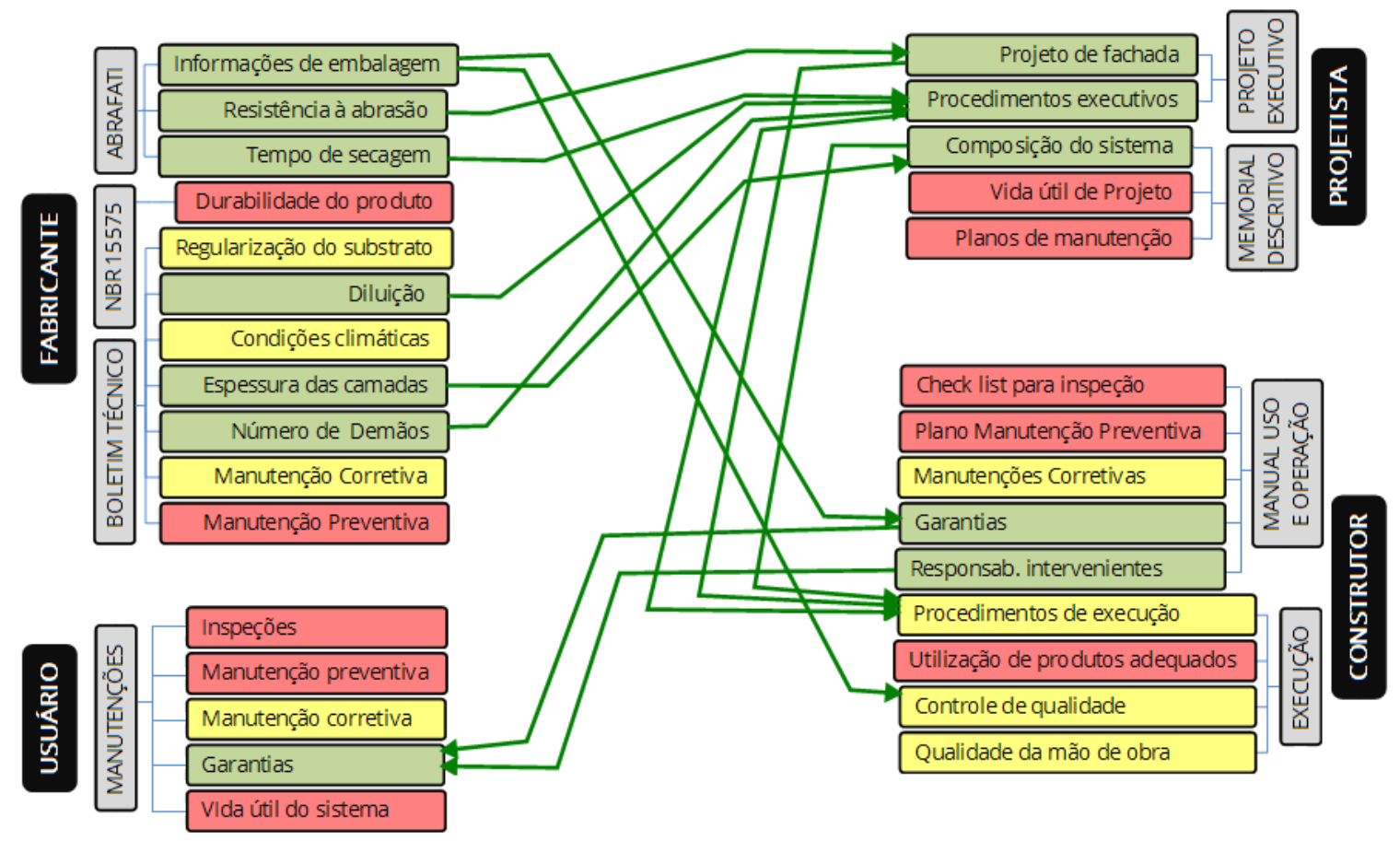

Aspectos atendidos com relação ao processo de pintura e normas ABNT
Aspectos parcialmente atendidos com relação ao processo de pintura e normas ABNT
Aspectos em descordo com relação ao processo de pintura e normas ABNT

Analisando a Figura 3 é possível constatar que, com relação ao desempenho, a durabilidade dos produtos e os procedimentos para manutenção preventiva sob responsabilidade dos fabricantes são dois aspectos insatisfatórios. Os resultados da pesquisa mostram que os fabricantes não caracterizam a vida útil de projeto de seus produtos, tendo como justificativa a complexidade e variedade de influentes no desempenho do sistema, as quais são condições para a vida útil do sistema e não para a VUP. Como consequência, os projetistas alegam impossibilidade de elaboração e especificação da VUP para os sistemas de pintura por conta da falta de informações técnicas dispostas pelos fabricantes. Entretanto, a NBR 15575-1 (ABNT, 2013a) orienta que, para situações em que os fabricantes não apresentem todas as informações necessárias para dimensionar o desempenho dos produtos, é de responsabilidade dos projetistas buscar técnicas, ensaios e soluções que busquem atender às exigências feitas por tal norma. Enfim, sem a VUP especificada pelos projetistas, os construtores não possuem parâmetros para balizar e selecionar os produtos e respectivos fabricantes com base no desempenho projetado, ficando evidente a escolha ou definição dos fornecedores em virtude do preço ou histórico de qualidade conhecido no mercado (feedback).

Ainda com relação aos fabricantes, não foram identificados procedimentos para a manutenção preventiva dos sistemas de pintura, sendo que a única prática encontrada ou descrita por eles foi a execução de lavagem com água das superfícies pintadas e que não apresentaram indicações para os períodos ou intervalo entre os serviços de lavagem. Com isso, tornam-se questionáveis as práticas de especificação ou previsão da durabilidade dos sistemas de pintura, levando em conta o comportamento dos materiais ou sistemas com relação às manutenções ao longo da vida útil, pois não foram encontrados procedimentos elaborados para execução das manutenções preventivas em tais sistemas. As construtoras ou os projetistas responsáveis pela elaboração do manual de uso, operação e manutenção das edificações informaram que, para cada produto utilizado que compõe o sistema de pintura, simplesmente transcrevem-se as especificações feitas pelos fabricantes para o conteúdo do manual, deixando clara a carência de desenvolvimento dos procedimentos de manutenção.

Outra deficiência, sob a responsabilidade dos construtores na elaboração do manual de uso, operação e manutenção, relaciona-se ao desenvolvimento de uma lista de verificação das tarefas de inspeção, relatório, registro e manutenção dos sistemas de pintura. A análise feita nos manuais de uso operação e manutenção 
demonstrou que a lavagem com água das superfícies pintadas e a repintura de áreas danificadas são os únicos procedimentos desenvolvidos para manutenção dos sistemas de pintura, deixando várias incertezas com relação à caracterização e avaliação da necessidade de intervenções no desempenho do sistema.

Em relação às informações dispostas nos manuais de uso, operação e manutenção das edificações, com relação a procedimentos e planos de manutenção corretiva e preventiva para os sistemas de pintura, a maioria dos manuais analisados especificou como procedimento de manutenção a repintura das superfícies externas no período de 2 anos e alguns especificaram a repintura de todas as superfícies externas a cada 1 ano. Tais dados mostram que os prazos estipulados nos manuais para repintura dos sistemas estão em desacordo com a vida útil mínima exigida pela norma de desempenho de 8 anos para pintura externa, tornando as manutenções inviáveis economicamente por conta do intervalo tão curto entre os serviços de repintura; tendo em vista que a NBR 15575-1 (ABNT, 2013a) considera atendido o requisito de VUP decorridos $50 \%$ do prazo para situações em que não haja histórico de intervenções significativas nos sistemas. Entretanto, a norma não caracteriza ou mensura o que são intervenções significativas. O capítulo 14.3 da NBR 15575-4 (ABNT, 2013b) descreve que a capacidade funcional de um sistema deve ser mantida durante a vida útil de projeto desde que seja submetida a intervenções periódicas de manutenção especificadas pelos próprios fornecedores. Constata-se que os fornecedores de tintas especificam limpezas ou lavagem anuais das superfícies pintadas como procedimento de manutenção. Para manchas, bolhas, desbotamento e descascamento, a orientação feita pelos fornecedores é para execução de repintura em todas as superfícies afetadas, trazendo à tona diversas dúvidas com relação à classificação desses procedimentos dentro das "intervenções significativas” mencionadas na NBR 15575-1 (ABNT, 2013a).

Quando as responsabilidades por parte dos usuários são analisadas, que conforme a NBR 15575-1 (ABNT, 2013a) devem executar a gestão e manutenção da edificação, fica clara a dificuldade em realizar inspeções sem uma lista de verificação com critérios e aspectos definidos e procedimentos de manutenção, sendo que os manuais de uso, operação e manutenção não preveem um programa ou plano elaborado.

Em análise ao disposto na NBR 15575-1 (ABNT, 2013a) e respectivas normas referenciadas, não foi possível detectar os critérios para inspeção ou classificação dos sistemas de pintura como conformes ou não conformes com relação ao requisito de desempenho. A falta de subsídios para inspeção dos sistemas de pintura tende a gerar conflito de interesses e possibilidade para diferentes interpretações como, por exemplo: o desbotamento do filme pode ser um aspecto que torna o sistema de pintura insuficiente ou pode estar associada apenas à percepção dos usuários quanto à aparência ou a características de apelo estético da edificação?

A norma de desempenho segrega as responsabilidades da construção civil entre seus intervenientes, atribuindo aos fabricantes a incumbência de executar os ensaios e atestar o desempenho de seus produtos. Entretanto, os fabricantes de tintas apontam que nem todos os ensaios deveriam ser de sua responsabilidade, uma vez que seu produto é apenas um componente de um sistema de fachada, sendo que, para atender às solicitações de desempenho, dependerá de variáveis como: deformações nos elementos de vedação vertical, traço e condições da argamassa de acabamento, condições do substrato, características climáticas no momento da aplicação, qualidade da mão de obra, dentre outros. Por outro lado, está consagrado na literatura técnica que o fabricante de um produto testa seu desempenho fixando as especificações do sistema e que os resultados do ensaio são válidos desde que mantidas essas especificações complementares. Portanto, esses ensaios deveriam ser providenciados pelos fabricantes para atestar o desempenho dos seus produtos.

Tendo em vista o descompasso das práticas do mercado com relação às exigências normativas, foi possível identificar algumas ações já propostas que tendem a contribuir para a qualidade dos sistemas de pintura nas edificações, tais como a utilização de painéis testes para cada fachada das edificações, desenvolvidos diretamente no canteiro de obras. Tais painéis poderiam ser replicados para os sistemas de pinturas convencionais, gerando dados do comportamento do sistema de pintura no próprio ambiente de trabalho, balizando assim as decisões em projeto (BRITEZ, 2007) e uma ficha de controle de conformidades para cada procedimento de pintura que deverá ser validado pelo responsável técnico diretamente na ficha de inspeção (MARQUES, 2013).

Para os critérios parcialmente atendidos pelos intervenientes apresentados na Figura 4, observou-se que 15 dos 25 fabricantes de tintas não apresentam no boletim técnico dos seus produtos especificações para cuidados e avaliação das condições do substrato no momento da aplicação do produto. Tal deficiência tende a contribuir para redução da vida útil dos sistemas de pintura quando considerada a aplicação da tinta em um substrato que necessita de um material regularizador, afetando diretamente no controle de qualidade do serviço. 
Conforme apontado pela revisão bibliográfica, a umidade de ar é um fator muito importante no surgimento de patologias no sistema, tais como bolhas ou descascamento da tinta. Tanto os cuidados com condições ambientais quanto as características do substrato influenciam diretamente nos procedimentos executivos de responsabilidade dos construtores. Entretanto, a especificação desses critérios não garante a eliminação dos problemas, uma vez que depende também do comprometimento da mão de obra em atender a todos os cuidados especificados.

Os procedimentos necessários para manutenção corretiva também foi um aspecto parcialmente atendido pelos fabricantes, pois apenas 15 dos 25 fabricantes propuseram procedimentos de serviços corretivos para os sistemas de pintura, o que tende a afetar a elaboração dos manuais de uso, operação e manutenção de responsabilidade das construtoras. Isso implica diretamente a execução das manutenções por parte dos usuários, tendo em vista que as especificações e procedimentos não estão dispostos no manual. Junto a isso, a presente falta de dados de durabilidade das tintas dificulta a análise dos usuários na caracterização de patologias e no acionamento dos serviços de garantia com os fornecedores, construtores e até mesmo os projetistas.

Com relação aos aspectos caracterizados como suficientes ou atendidos pelos intervenientes da construção, percebe-se que todas as características atendidas pelos fabricantes tendem a influenciar diretamente nas considerações de projeto, com exceção das informações de embalagem e validade dos produtos, estas relacionadas diretamente às construtoras, conforme visto na Figura 5. A Abrafati, baseada em uma série de normas que estabelecem os requisitos de desempenho para tintas para construção civil, como as NBR 150791 e 15079-2 (ABNT, 2019b, 2019c), inspeciona trimestralmente a qualidade das tintas, avaliando as informações de embalagem dos produtos, os prazos de validade, o poder de cobertura, tanto da tinta seca quanto da tinta úmida, a resistência à abrasão, o tempo de secagem, o teor de sólidos da solução e a determinação do brilho com base na reflexão da luz. Além disso, as tintas devem apresentar todas essas informações em um boletim técnico, agregando dados de diluição do produto, espessura das camadas do material aplicado e o número de demãos, sendo estes aspectos considerados atendidos pelos fabricantes.

Em análise às incumbências dos projetistas, eles destacaram que, para todos os edifícios de sua responsabilidade técnica, elabora-se o projeto de fachada com especificações de produtos e procedimentos executivos.

Os aspectos relacionados aos memoriais e projetos executivos, estes diretamente ligados aos procedimentos de execução desempenhados no canteiro de obras, foram considerados atendidos, visto que foi constatada, durante a entrevista, a prática dos projetistas de transcreverem em seus memoriais as especificações feitas pelos fabricantes que atendem a todos os aspectos influentes na elaboração dos memoriais executivos e desenvolvimento da composição dos sistemas de pintura.

Já os construtores atenderam apenas às especificações de garantias e caracterização dos intervenientes responsáveis, mas, apesar de caracterizados, não possuíam subsídios claros para as inspeções. Contudo, considerou-se atendido pela consideração, neste estudo, das inspeções como um procedimento de manutenção e não de garantia. Por fim, fica claro que o único aspecto atendido ao alcance dos usuários é com relação às garantias. Porém, a garantia não é completamente suficiente se analisada em conjunto com os procedimentos de inspeção e manutenção, sendo que, para a garantia de desempenho e durabilidade dos produtos, os procedimentos de manutenção devem ser executados dentro de um plano pré-estabelecido.

\section{Considerações finais}

Este estudo buscou identificar e expor as barreiras e dificuldades na determinação e especificação do desempenho e vida útil dos sistemas de pintura externa de acordo com as exigências feitas pela norma de desempenho. O mapa mental desenvolvido representou a interligação entre os principais procedimentos e aspectos para composição do sistema de pintura externa, evidenciando os processos que não atendem às exigências normativas e acabam contribuindo para que as tarefas subsequentes da cadeia executiva não atendam aos requisitos da norma de desempenho.

As contribuições científicas estão ligadas à constatação de que a cadeia de intervenientes da norma de desempenho está firmemente relacionada e que, quando um elo da cadeia produtiva não é observado, gera o descumprimento de todos os elos subsequentes. Além disso, as normas técnicas não definem critérios para classificar o sistema de pintura como conforme ou não conforme com relação ao desempenho. Portanto, é necessária a definição de um critério de desempenho para avaliação do sistema de pintura em revestimentos argamassados.

138 Bordin, M. F.; Lantelme, E. M. V.; Costella, M. F. 
Dentre as contribuições práticas do trabalho, pode-se destacar a necessidade de que os fornecedores de tinta, em sua totalidade, forneçam os dados de vida útil, durabilidade e detalhem os aspectos de execução do seu produto. Para os construtores e incorporadores, evidencia-se a necessidade de especificar prazos de manutenção que respeitem os prazos de vida útil estabelecidos pelos projetistas, tendo em vista que os procedimentos de manutenção estipulados nos manuais de uso, operação e manutenção das edificações possuem intervalos muito curtos entre as intervenções, tornando tais ações inviáveis economicamente. Quanto aos projetistas, constatou-se que ainda utilizam técnicas prescritivas para especificação, não levando em conta a durabilidade dos produtos e o desempenho do sistema.

Dentre as limitações da pesquisa, destaca-se que a análise de manuais de uso, operação e manutenção e as entrevistas com projetistas foram realizadas em amostra restrita e não probabilística e que, portanto, é possível haver realidades distintas em outros locais do país. Por outro lado, como a análise dos fornecedores foi nacional e são eles os precursores da cadeia, as contribuições sobre os elos da cadeia permanecem válidas.

Apesar da norma de desempenho ter sido elaborada para atender às exigências dos usuários, garantindo a qualidade das edificações brasileiras, para que o mercado se aproxime do objetivo proposto, torna-se necessária a incorporação dessas práticas de desempenho por parte dos fabricantes na fabricação e ensaios dos produtos; dos projetistas, na especificação dos projetos e planos de manutenção que levem em conta a vida útil dos produtos; das construtoras, no controle de qualidade de execução dos serviços e proposição de plano de manutenção que atende à norma; e dos usuários, no comprometimento e efetividade nas práticas de manutenção.

Como sugestão para trabalhos futuros, pode-se verificar a possibilidade dos projetistas, dos construtores e dos usuários realizarem as suas incumbências relacionadas ao desempenho sem as informações dos fornecedores dos sistemas de pintura.

\section{Referências}

ALMEIDA, M. L. D. Critérios para realização de pintura de alvenarias em ambientes não agressivos. Belo Horizonte, 2012. 97 f. Dissertação (Mestrado em Engenharia Civil) - Universidade Federal de Minas Gerais, Belo Horizonte, 2012.

ASSOCIAÇÃO BRASILEIRA DE NORMAS TÉCNICAS. NBR 11702: tintas para construção civil: tintas, vernizes, texturas e complementos para edificações não industriais: classificação e requisitos. Rio de Janeiro, 2019a.

ASSOCIAÇÃO BRASILEIRA DE NORMAS TÉCNICAS. NBR 13245: tintas para construção civil: execução de pinturas em edificações não industriais: preparação de superfície. Rio de Janeiro, 2011.

ASSOCIAÇÃO BRASILEIRA DE NORMAS TÉCNICAS. NBR 14037: diretrizes para elaboração de manuais de uso, operação e manutenção das edificações: requisitos para elaboração e apresentação dos conteúdos. Rio de Janeiro, 2014.

ASSOCIAÇÃO BRASILEIRA DE NORMAS TÉCNICAS. NBR 15079-1: tintas para construção civil: requisitos mínimos de desempenho: parte 1: tinta látex fosca nas cores claras. Rio de Janeiro, $2019 \mathrm{~b}$.

ASSOCIAÇÃO BRASILEIRA DE NORMAS TÉCNICAS. NBR 15079-2: tintas para construção civil: requisitos mínimos de desempenho: parte 2: tintas látex semiacetinada, acetinada e semibrilho nas cores claras. Rio de Janeiro, 2019c.

ASSOCIAÇÃO BRASILEIRA DE NORMAS TÉCNICAS. NBR 15575-1: edificações habitacionais: desempenho: parte 1: requisitos gerais. Rio de Janeiro, 2013a.

ASSOCIAÇÃO BRASILEIRA DE NORMAS TÉCNICAS. NBR 15575-4: edificações habitacionais: desempenho: parte 4: requisitos para os sistemas de vedações verticais internas e externas. Rio de Janeiro, 2013 b.

ASSOCIAÇÃO BRASILEIRA DE NORMAS TÉCNICAS. NBR 5674: manutenção de edificações: requisitos para o sistema de gestão de manutenção. Rio de Janeiro, 2012.

BELÉM, K. G. de S.; STARLING, C. M. D.; ANDERY, P. R. P. Impactos e desafios associados com a implantação da norma de desempenho em edificações prediais. In: ENCONTRO NACIONAL DE TECNOLOGIA DO AMBIENTE CONSTRUÍDO, 17., Foz do Iguaçu, 2018. Anais [...] Porto Alegre: ANTAC, 2018. 
BORGES, C. A. D. M. O conceito de desempenho de edificações e a sua importância para o setor da construção civil no Brasil. São Paulo, 2008. 263 f. Dissertação (Mestrado em Engenharia Civil) - Escola Politécnica, Universidade de São Paulo, São Paulo, 2008.

BRASIL, P. D. C.; SALGADO, M. S. A influência da gestão do processo de projeto na durabilidade das edificações. In: ENCONTRO NACIONAL DE TECNOLOGIA DO AMBIENTE CONSTRUIDO, 14., Juiz de Fora, 2012. Anais [...] Porto Alegre, ANTAC, 2012.

BRITEZ, A. A. Diretrizes para especificação de pinturas externas texturizadas acrílicas em substrato de argamassa. São Paulo, 2007. 148 f. Dissertação (Mestrado em Engenharia Civil) - Escola Politécnica, Universidade de São Paulo, São Paulo, 2007.

CÂMARA BRASILEIRA DA INDÚSTRIA DA CONSTRUÇÃO. Desempenho de Edificações Habitacionais: guia orientativo para atendimento à norma ABNT NBR 15575/2013. Brasília, 2013. Disponível em: https://site.abece.com.br/download/pdf/130626CBICGuiaNBR2EdicaoVersaoWeb.pdf. Acesso em: 24 abr. 2020.

CARRARO, C. L.; DIAS, J. F. Diretrizes para prevenção de manifestações patológicas em Habitações de Interesse Social. Ambiente Construído, Porto Alegre, v. 14, n. 2, p. 125-139, abr./jun. 2014.

CORDOVIL, L. A. B. L. Estudo da ABNT NBR 15575 - "Edificações habitacionais - Desempenho" e possíveis impactos no setor da construção civil na cidade do Rio de Janeiro. Rio de Janeiro, 2013. 62 f. Dissertação (Mestrado em Engenharia Civil) - Universidade Federal do Rio de Janeiro, Rio de Janeiro, 2013.

COSTELLA, M. F. Norma de desempenho de edificações: modelo de aplicação em construtoras. Curitiba: Appris, 2018.

CUNHA, A. D. O. O estudo da tinta/textura como revestimento externo em substrato de argamassa. Belo Horizonte, 2011. 117 f. Dissertação (Mestrado em Engenharia Civil) - Escola de Engenharia, Universidade Federal de Minas Gerais, Belo Horizonte, 2011.

FRANGOPOL, D. M. Life-cycle performance, management, and optimisation of structural systems under uncertainty: accomplishments and challenges. Journal of Structure and Infrastructure Engineering, v. 7, n. 6, p. 389-413, May 2011.

GIUDICE, C. A.; PEREYRA, A. M. Control de calidad de películas de pinturas. La Plata: Editora Universitaria de la U.T.N., 2015. Centro de Investigación y Desarrollo en Tecnológica Nacional Facultad Regional La Plata.

GRANDISKI, P. Olhar de perito. Revista Téchne, São Paulo, v. 87, jun. 2004.

KERN, A. P.; SILVA, A.; KAZMIERCZAK, C. S. O Processo de implantação de normas de desempenho na construção: um comparativo entre a Espanha (CTE) e Brasil (NBR 15575/2013). Gestão e Tecnologia de Projetos, São Paulo, v. 9, n. 1, p. 89-101, jun. 2014.

LEWRY, A. J.; CREWDSON, L. F. E. Approaches to testing the durability of materials used in the construction and maintenance of buildings. Construction and Building Materials, v. 8, n. 4, p. 211-222, 1994.

LUND, S.; LAMEGO, F. Análise comparativa do levantamento das manifestações patológicas em conjuntos habitacionais para população de baixa renda. In: SEMANA INTERNACIONAL DE INVESTIGACIÓN FAULTAD DE ARQUITECTURA Y URBANISMO, Caracas, 2008. Proceedings [...] Caracas: Técnología Constructiva, Universidad Central de Venezuela, 2008.

MARQUES DE JESUS, C. R. Análise de custos para reabilitação de edifícios para habitação. São Paulo, 2008. 178 f. Dissertação (Mestrado em Engenharia Civil) - Escola Politécnica da Universidade de São Paulo, São Paulo, 2008.

MARQUES, F. P. F. M. Tecnologias de aplicação de pinturas e patologias em paredes de alvenaria e elementos de betão. Lisboa, 2013. 137 f. Dissertação (Mestrado em Engenharia Civil) - Instituto Superior Técnico de Lisboa, Lisboa, 2013.

MAYER, P. D.; BOURKE, K. P. Durability rankings for building component service life prediction. In: INTERNATIONAL CONFERENCE ON DURABILITY OF BUILDINGS MATERIALS \& COMPONENTS, 10., Lyon, 2005. Proceedings [...] DBMC: Lyon, 2005.

140 Bordin, M. F.; Lantelme, E. M. V.; Costella, M. F. 
OLIVEIRA PRIMO, A. D. D. Estudo da durabilidade de materiais e sistemas construtivos: sistema ETICS. Porto, 2008. 76 f. Dissertação (Mestrado em Engenharia Civil) - Faculdade de Engenharia, Universidade do Porto, Porto, 2008.

OLIVEIRA, L. A.; FONTENELLE, J. H.; MITIDIERI FILHO, C. V. Durabilidade de fachadas: método de ensaio para verificação da resistência à ação de calor e choque térmico. Ambiente Construído, Porto Alegre, v. 14, n. 4, p. 53-67, out./dez. 2014.

OLIVEIRA, M. M. F. D. O impacto da NBR 15575/13 (norma de desempenho) na concepção de projetos e da construção. Revista Especialize On-line, v. 1, n. 11, jul. 2016.

PAGLIARI, C. S. et al. Dificuldades na implantação da norma de desempenho em construtoras de médio e pequeno porte no oeste de Santa Catarina. Revista de Arquitetura IMED, Passo Fundo, v. 8, n. 2, p. 97118, dez. 2019.

PAGLIARI, C. S.; COSTELLA, M. F.; PILZ, S. E. Especificação da vida útil dos sistemas construtivos a partir da NBR 15575, segunda a abordagem de projetos. PARC Pesquisa em Arquitetura e Construção, Campinas, v. 9, n. 1, p. 47-56, mar. 2018.

PALLAORO, A. M. et al. Análise de manuais de uso, operação e manutenção de edificações habitacionais com foco na norma de desempenho. In: ENCONTRO NACIONAL DE TECNOLOGIA DO AMBIENTE CONSTRUIDO, 17., Foz do Iguaçu, 2018. Anais [...] Porto Alegre: ANTAC, 2018.

POLITO, G. Principais sistemas de pinturas e suas patologias. Minas Gerais: Departamento de Engenharia de Materiais e Construção, Universidade Federal de Minas Gerais, 2006. Disponível em: http://aprendercomoganhardinheiro.com/wp-content/uploads/2016/06/Apostila-de-pintura-GiullianoPolito.pdf. Acesso: 04 dez. 2017.

RESENDE, M. M.; BARROS, M. M. S. B.; MEDEIROS, J. S. A influência da manutenção na durabilidade dos revestimentos de fachada de edifícios. In: WORKSHOP SOBRE DURABILIDADE DAS CONSTRUÇÕES, 2., São José dos Campos, 2001. Anais [...] São José dos Campos: WORKDUR, 2001.

SEGAT, G. T. Manifestações patológicas observadas em revestimentos de argamassa: estudo de caso em conjunto habitacional popular na cidade de Caixas do Sul (RS). Porto Alegre, 2005. 166 f. Dissertação (Mestrado em Engenharia Civil) - Escola de Engenharia, Universidade Federal do Rio Grande do Sul, Porto Alegre, 2005.

SHERWIN, D. A review of overall models for maintenance management. Journal of Quality in Maintenance Engineering, v. 6, n. 3, p. 138-164, 2000.

TAVARES, A. D. C. Gestão de edifícios: informação comportamental. Porto, 2009. 71 f. Dissertação (Mestrado em Engenharia Civil) - Faculdade de Engenharia, Universidade do Porto, Porto, 2009.

WALDHELM, C. Manifestações patológicas em unidades habitacionais de baixo padrão do Jardim Colúmbia em Londrina-PR. Londrina, 2014. 117 f. Dissertação (Mestrado em Engenharia Civil) Universidade Estadual de Londrina, Londrina, 2014.

YIU, C. Y. Intelligent building maintenance: a novel discipline. Journal of Building Appraisal, v. 3, n. 4, p. 305-317, Feb. 2008. 
Mateus Flores Bordin

Programa de Pós-Graduação em Engenharia Civil | Faculdade Meridional IMED | Rua Gen. Prestes Guimarães, 304, Vila Rodrigues | Passo Fundo - RS - Brasil | CEP 99070-220 | Tel.: (54) 3045-6100 | E-mail: mateus-bordin@hotmail.com

Elvira Maria Vieira Lantelme

Programa de Pós-Graduação em Engenharia Civil | Faculdade Meridional IMED | E-mail: elvira.lantelme@imed.edu.br

\section{Marcelo Fabiano Costella}

Programa de Pós-Graduação em Tecnologia e Gestão da Inovação | Unochapecó | Servidão Anjo da Guarda, 295-D, Efapi | Chapecó - SC Brasil | CEP 89809-900 | Tel.: (49) 3321-8111 | E-mail: costella@unochapeco.edu.br

\section{Ambiente Construído}

Revista da Associação Nacional de Tecnologia do Ambiente Construído Av. Osvaldo Aranha, $99-3^{\circ}$ andar, Centro

Porto Alegre - RS - Brasil

$$
\text { CEP 90035-190 }
$$

Telefone: +55 (51) 3308-4084

$$
\begin{aligned}
& \text { www.seer.ufrgs.br/ambienteconstruido } \\
& \text { www.scielo.br/ac }
\end{aligned}
$$

E-mail: ambienteconstruido@ufrgs.br 